\title{
FURTHER OBSERVATIONS ON THE FINE STRUCTURE OF CHRYSOCHROMULINA MINOR AND C. KAPPA WITH SPECIAL REFERENCE TO THE PYRENOIDS
}

\author{
By I. Manton, F.R.S., AND G. F. Leedale \\ Botany Department, Leeds University
}

(With 24 Figures on Plates I-VI)

Apart from the external appendages (flagella and haptonema), for which effective methods of study are now standard, the most difficult body in cells of the Chrysophyceae to investigate with the light microscope is the pyrenoid. The reason for this is mainly that the criteria available for recognizing pyrenoids in living cells of this group are all negative, i.e. a pyrenoid is a colourless region in a small and often rather pale plastid which does not stain with any of the usual reagents giving diagnostic colour reactions with other cell components. This contrasts markedly with the state of affairs in the Chlorophyceae for which pyrenoids, when present, are conspicuous and easily demonstrable by positive criteria such as presence of starch. Nevertheless, the existence of a specialized storage area within or attached to plastids of the Chrysophyceae has been suggested by more than one light-microscopist (for literature, see Parke, Manton \& Clarke, 1958), and the electron microscope has provided the strongest possible supporting evidence for this supposition.

This notwithstanding, the difficulty in detecting pyrenoids at will with the light microscope is a real one, and until it can be circumvented by chemical knowledge leading to a diagnostic colour reaction, or in some other way, the electron microscope remains an indispensable instrument for establishing the basic facts. This has already been done to the extent of revealing that two rather different types of pyrenoid can be encountered among the array of species so far described under the comprehensive genus Chrysochromulina. In one species, $C$. chiton, which was also the first for which the results from thin sections were available at the time of the taxonomic description (Parke, Manton \& Clarke, I958), the pyrenoid is a subspherical body attached to the inner face of a plastid by a narrow neck and densely filled with electron opaque storage material traversed by a few apparently empty canaliculi. In another species, C. strobilus (Parke, Manton \& Clarke, I959), a deeply immersed storage region also traversed by canaliculi was found in the centre of each plastid, the canaliculi in this case being traceable as the inner extensions of some of the plastid lamellations proper, which in the storage region become converted into closely paired tubes. Other examples of pyrenoids of this 
type have subsequently been added (notably C. ericina, C. alifera and C. ephippium in Manton \& Leedale, 1961 $a$, and C. brevifilum in Manton, 1961) but no others resembling $C$. chiton. The apparently isolated condition of this species is therefore a stumbling block to any unified treatment of the genus as a whole, and this difficulty cannot be resolved without further information.

Much new information has now come from a re-investigation of two of the earliest studied marine species of Chrysochromulina, originally described without the aid of sections (Parke, Manton \& Clarke, 1955). Both C. minor and C. kappa differ from the other species enumerated above in having a smaller average cell size and a considerably shorter haptonema. This appendage is indeed so short as to be actually less than the flagella in length in a majority of cells; it is therefore superficially more like a flagellum than in any of the better known species. In addition, bodies thought to be pyrenoids but outside the plastids had been somewhat tentatively described for each, the fullest account being that given for C. kappa in terms as follows (Parke et al., I955, p. 589). 'A conspicuous refringent body, perhaps equivalent to the so-called pyrenoid of some authors, is situated near the centre of the inner face of each chromatophore. These bodies vary in size and sometimes appear to be surrounded by nonrefringent material. They appear to divide at the same time as the chromatophores, but it is not known whether they are actually attached to the inner face...' These various points of uncertainty are the special reasons for selecting these two species for further study, and in the presentation of the new observations reference to other matters of interest will only be made incidentally, as opportunity permits, within the framework of a primary interest in pyrenoids and haptonemata.

The technical methods employed are exactly as on previous occasions except that for $C$. kappa a shortening of the fixation time from $\mathrm{I}$ h to Io $\mathrm{min}$ gave greatly improved results. The details for the use of anoptral contrast for the few supplementary observations on living cells will be found in Manton \& Leedale (I96r $a$ ). Finally the source of material has in each case been the type culture supplied from Plymouth by Dr Parke. The reference numbers in the Plymouth collection are $\mathrm{K}$ for $C$. kappa and 52 for $C$. minor as explained in Parke et al. (1955).

We are grateful to the Development Commission for financial assistance, to $\operatorname{Dr}$ M. Parke for supplying cultures and reading the manuscript, and to Mr K. Oates and Miss Sheila Wright for help in preparing the plates for publication and in many other ways.

\section{NEW OBSERVATIONS ON CHRYSOCHROMULINA MINOR}

It will be convenient to consider $C$. minor first since, although only slightly smaller than C. kappa (compare, for example, P1. I, figs. I and 2), the internal structure is a little simpler and more easily described. Except for these two 
figures it will also be convenient to deal first with the electron microscopy of sections since understanding of the latter has been, in our experience, essential for the effective further use of the light microscope.

In comparison with the small cell size of this organism the pyrenoids when seen with the electron microscope are large and conspicuous. In transverse section (P1. III, fig. I3; Pl. IV, figs. I6, I8) the profiles are approximately circular with an average diameter of the order of $\mathrm{I} \mu$. When cut longitudinally the pyrenoids are clearly ovate, slightly narrowed at the base and commonly curved to lie along one face of the subtending plastid (P1. II, fig. I2). It is not easy to distinguish a median longitudinal section from an oblique or tangential one, and therefore the maximum length is slightly uncertain but is of the order of $2 \mu$.

The base of a pyrenoid is attached near the centre of the inner face of the subtending plastid. The most critical evidence for this position is a series of transverse sections through the point of attachment from which two sample levels are reproduced in Pl. IV, figs. I7, I8.

The compound surface-membrane of the plastid can be seen in longitudinal sections to continue without interruption over the surface of the pyrenoid. Internally a few of the lamellations from the pigmented region of the plastid continue into the storage region (see especially Pl. II, fig. II). Here they may yield circular or apparently cylindrical profiles (P1. II, fig. I2; P1. IV, figs. I6, I8) according to the plane of section, or, in early division stages (e.g. Pl. II, fig. I0), more contorted shapes. Occasionally an array of closely packed lamellations may line the surface of a pyrenoid (e.g. P1. III, fig. $1_{3}$, on the side touching the nucleus). The interpretation of this feature is uncertain though it is possible that it is also in some way connected with an impending division.

The relation of the pyrenoids to other cell organelles, notably thenucleus, is of some interest. In this species the nucleus is commonly pressed closely to the surface of a plastid(Pl. III, fig. I3; Pl. IV, figs. I5, I6 and I8) conforming exactly to the underlying shape whether concave (Pl. IV, fig. I8) or convex (P1. III, fig. I3; Pl. IV, fig. I6). If it lies near to a pyrenoid the nucleus may become indented by it to a modest extent (e.g. Pl. IV, fig. I6), though there is no suggestion that this is more than incidental.

The nuclear surface is very intimately involved in these contacts. This is perhaps most clearly seen in P1. III, fig. I3, although at higher magnifications the sections of Pl. IV, figs. I6 and I8 show it at least as well. The perinuclear space separating nuclear contents from cytoplasmic contents (except where it is bridged by a 'pore') is continuous, but where the nucleus abuts on to the surface of either a plastid or a pyrenoid the membrane bounding the cytoplasmic side of the perinuclear space disappears. At the point of junction with the free part of the nuclear surface, continuity can be traced between the membrane bounding the cytoplasmic side of the perinuclear space and the 


\section{Explanation of Plates I-IV}

Plate I

Photographs of living cells taken with anoptral contrast, $\times 2000$

Fig. I. Chrysochromulina kappa. A swimming cell with extended haptonema and beating flagella.

Fig. 2. C. minor. A swimming cell with extended haptonema.

Figs. 3, 4. C. minor. Two different focal levels through a cell to show the emergence of the two flagella (fig. 3) and a profile view of the plastids and pyrenoids (fig. 4).

Fig. 5. C. minor. Another cell showing the attachment of the pyrenoids $(P y)$ to the inner face of each plastid.

Fig. 6. C. minor. Partly flattened cell showing the nucleus as a dark vesicle between a bright fat body and the two facing plastids with their pyrenoids.

Figs. 7-9. C. minor. Three successive stages of flattening by drying out of the preparation. Fig. 7 shows the two plastids with pyrenoids $(P y)$ in face view, the position of the nucleus $(N)$, the leucosin vesicle $(L)$, two fat bodies $(f)$ and the flagella; in fig. 8 the pyrenoids have burst, each leaving a bright granule; in fig. 9 striations have become visible within the considerably distorted plastids, the leucosin vesicle $(L)$ is still unburst.

\section{Plates II-IV. Electron micrographs of Chrysochromulina minor}

\section{Plate II}

Fig. 10. Section showing a lobed pyrenoid preparatory to division. Micrograph B650, $\times 20,000$,

Fig. Ir. Section showing a pyrenoid attached to each of two plastids or plastid halves. Micrograph B 582, × I5,000.

Fig. 12. Section containing a longitudinally cut pyrenoid $(P y)$, two plastids $(P)$, a mitochondrion $(m)$, a small piece of nucleus $(N)$ and vesicle $(x)$ containing a sectioned scale shown at a higher magnification in top inset. A section of scales on the body surface in the region of the arrow shown at a higher magnification in bottom inset. Micrograph B 260, $\times 20,000$; insets $\times 40,000$.

\section{Plate III}

Fig. 13. Section to show the relation of the nucleus $(N)$ with the surfaces of a plastid $(P)$ and a pyrenoid $(P y)$; details of the nuclear envelope and pyrenoid surface membrane resolved; a section of this cell at another level in fig. 15. Micrograph B 1361, $\times 40,000$.

Fig. I4. Three profiles from different parts of a section of a coiled haptonema showing in each case the three concentric membranes (the outer one distended) surrounding seven tubes or fibres. Micrograph B 274, $\times 60,000$.

\section{Plate IV}

Fig. 15. Another section of the cell of fig. I3 showing the attachment of the pyrenoid to the plastid. Micrograph Br376, $\times$ c. 12,000.

Fig. I6. Section near the flagellar pole showing a nucleus $(N)$ pressed closely to the surface of a plastid and pyrenoid. Micrograph B6r9, $\times 20,000$.

Figs. 17, r8. Sections from two different levels through the same cell, fig. 17 tangential and showing the base of a pyrenoid entering a plastid centrally, fig. 18 showing the nucleus $(N)$ between the pyrenoid $(P y)$ and the concave inner surface of one part of the plastid which is here transected twice; two mitochondrial profiles $(m)$ also shown. Micrographs B I354, × I0,000 (fig. I7), B I35 I, $\times 25,000$ (fig. 18). 

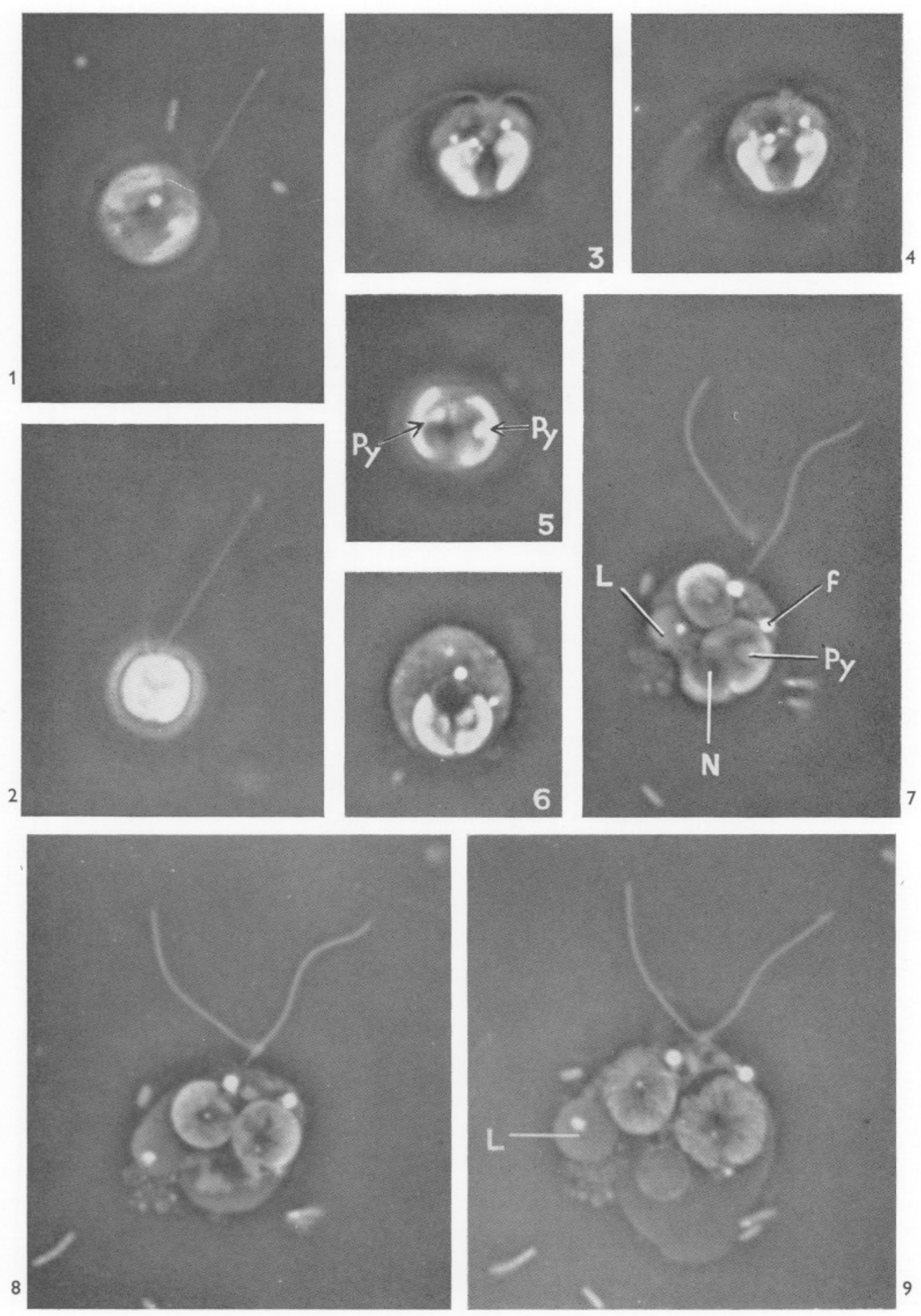

(Facing p. 522) 

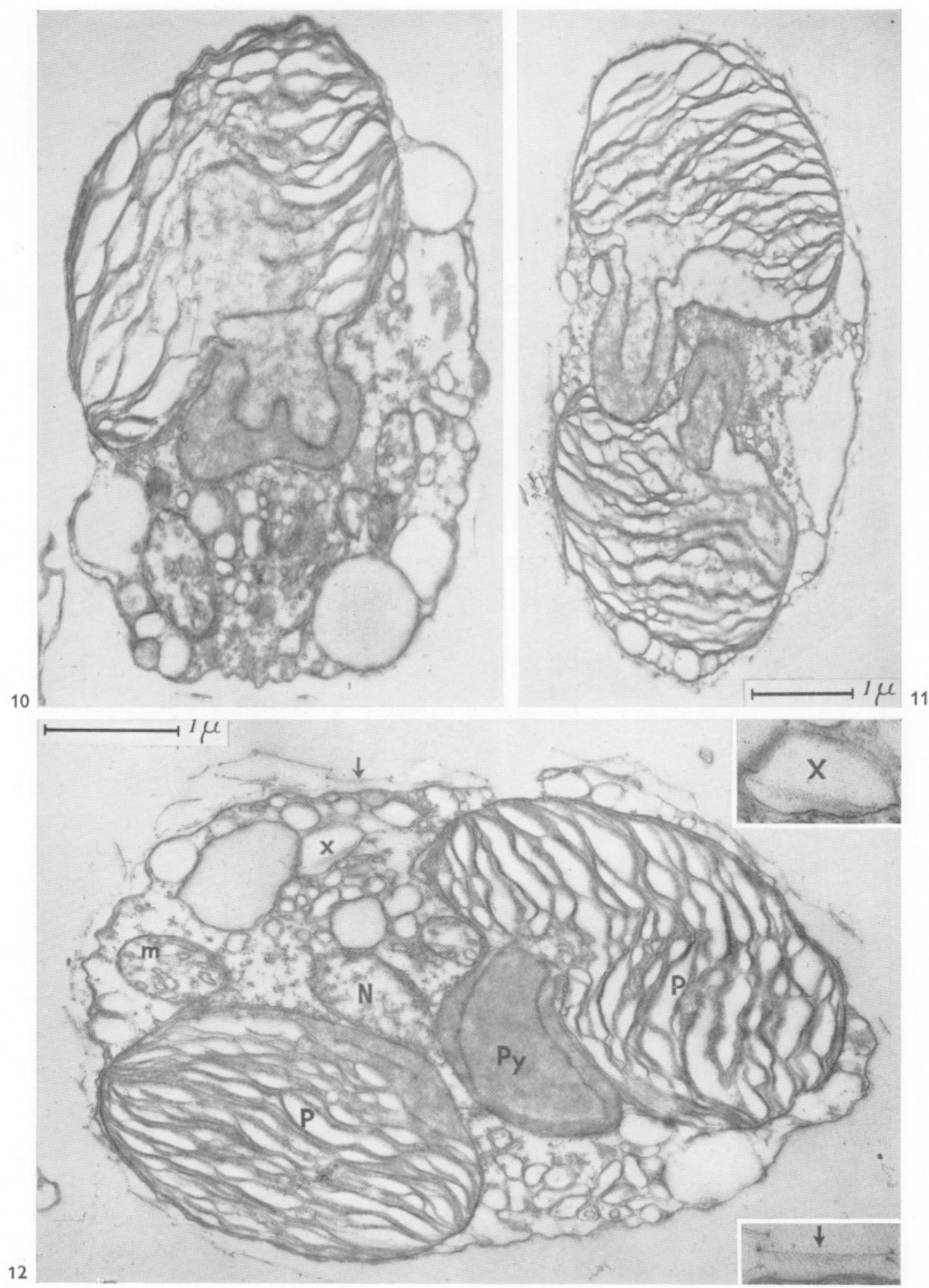


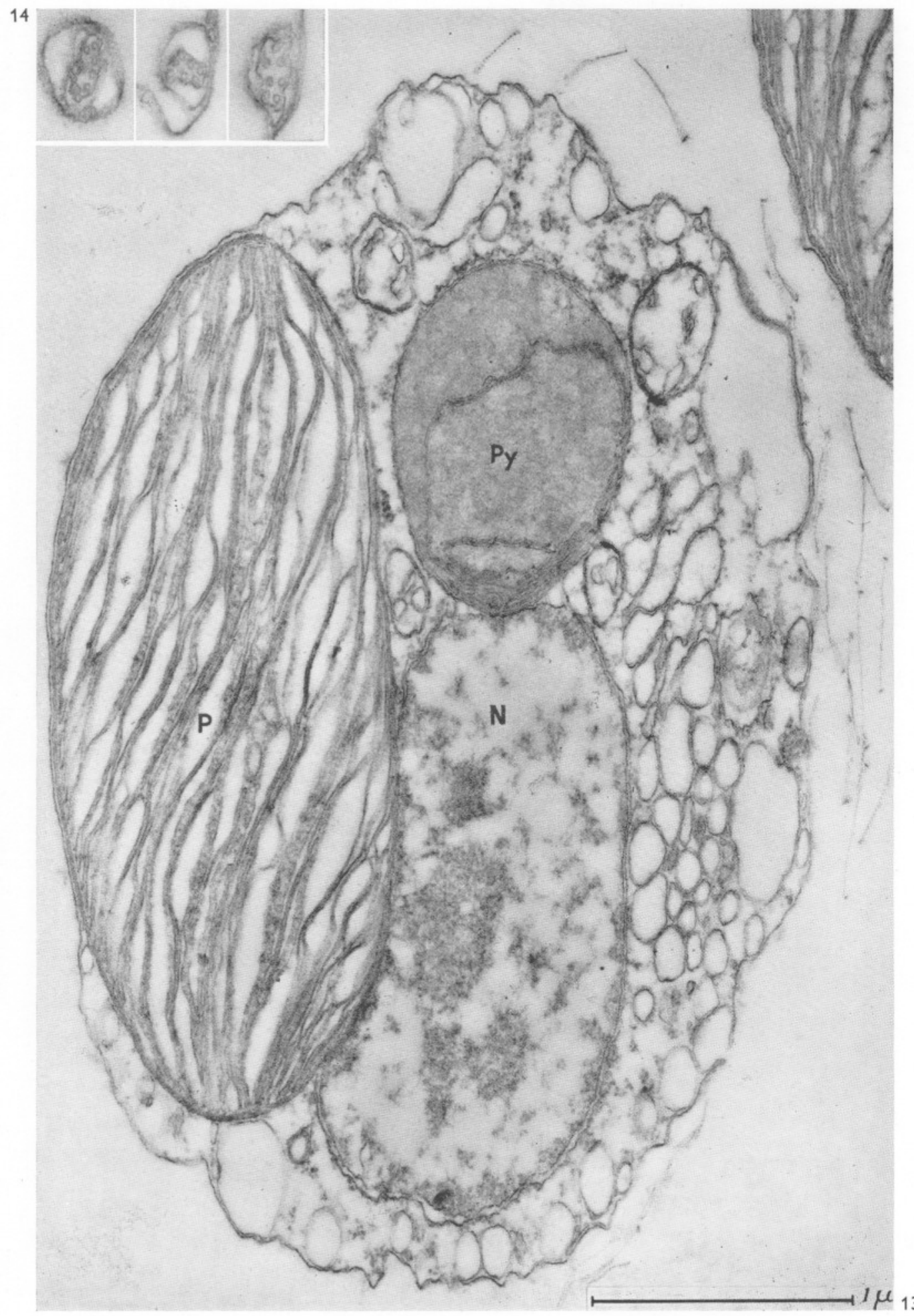




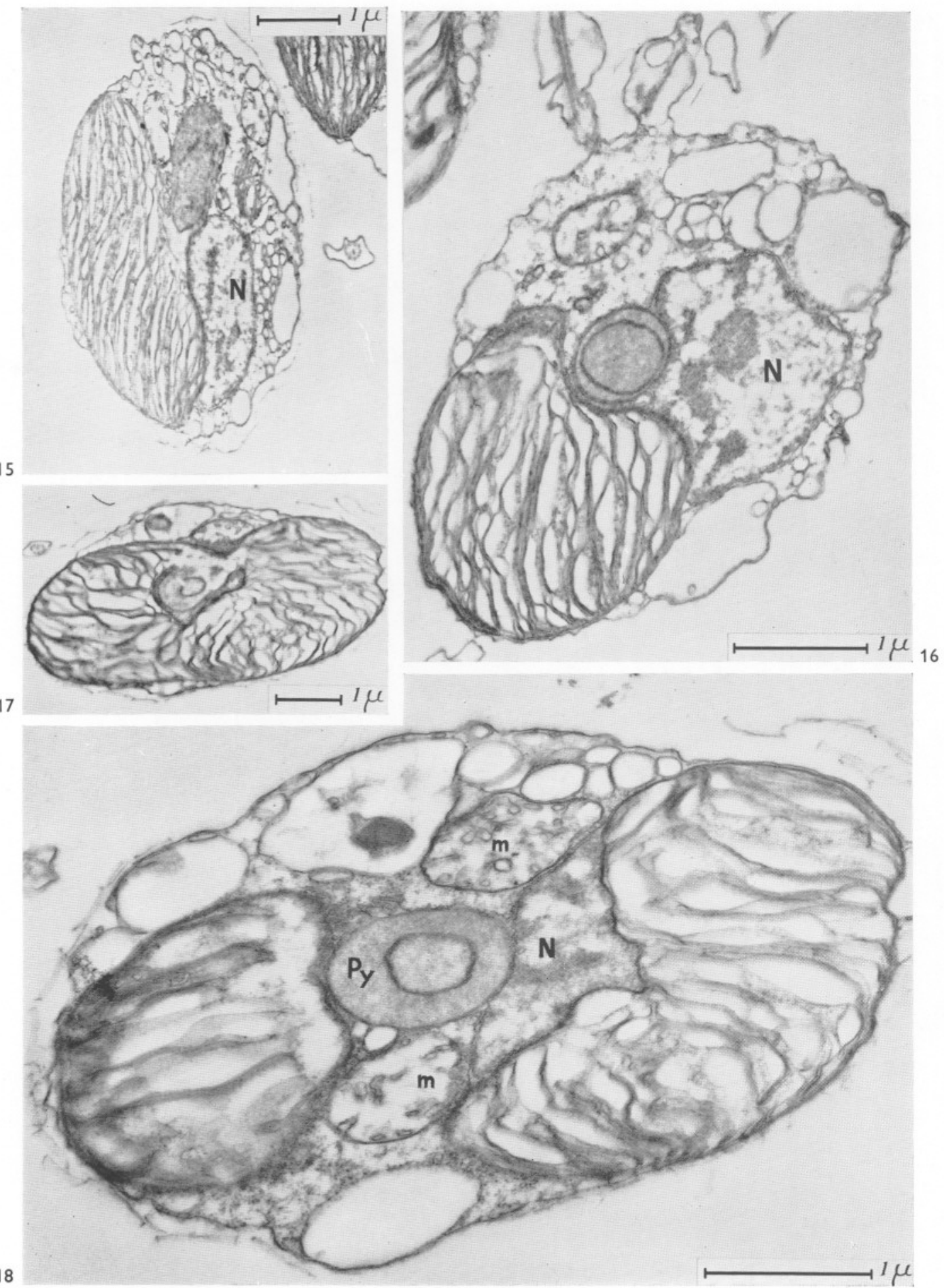


cytoplasmic boundary covering the plastid or pyrenoid. There is thus potentially an uninterrupted cavity enveloping the surfaces of both nucleus and plastid. This observation is of interest for the light it throws on the nature of the plastid surface itself. However, the physiological or other importance, if any, of this sharing of potential spaces is entirely unknown.

These facts having been established it was possible to study the living cells with anoptral contrast and to select favourable individuals in which the pyrenoids could be seen. Pl. I, figs. $3-6$, illustrate this, while figs. $7-9$ show the transformation which occurs when a cell becomes flattened by pressure from the coverslip as liquid from the mount evaporates. At first the pyrenoids appear circular (fig. 7), but as pressure increases they suddenly burst (fig. 8), each leaving a conspicuous bright granule of unknown nature behind.

The haptonema has been found to resemble closely the longer haptonemata of other anatomically known species and can be dealt with briefly. There are the usual three concentric membranes surrounding a ring of seven fibres (or tubes) and it will suffice to reproduce (Pl. III, fig. I4) three sample profiles from one specimen in illustration.

Attention can perhaps usefully be directed to one other detail, illustrated by the inset pictures on P1. II, fig. I2. In $C$. minor the fine sculpturing on the surfaces of the scales is more easily distinguishable in sections than is usual in the small-scaled species of Chrysochromulina, and we have several examples of scales encountered within vesicles, one of which happens to be included in the section in P1. II, fig. I2. The vesicle $(x)$ is shown more highly magnified in the top inset and some superficial scales are reproduced at the same magnification in the bottom inset. Though the complication of phagotrophic feeding should not be forgotten, these vesicles do not look like food vacuoles and are probably interpretable as evidence of internal scale production of the same general type as recently demonstrated more fully for Micromonas squamata (by Manton \& Parke, 1960) and Paraphysomonas vestita (by Manton \& Leedale, I96I $b$ ).

\section{NEW OBSERVATIONS ON CHRYSOCHROMULINA KAPPA}

This species proved to be much more difficult to investigate with the methods used here and it was necessary to modify the fixation procedure before satisfactory sections could be obtained. Shortening the fixation time from $\mathrm{I} h$ to Io min proved effective, after which it could be seen that the structure is essentially like that of $C$. minor except for the rather exaggerated behaviour of the nucleus.

As in C. minor the pyrenoid is attached centrally to the inner face of a plastid though it is less strongly flexed and may be longer. An average width of rather less than I $\mu$ is associated with a length of up to $2.5 \mu$. As in C. minor the pyrenoid undoubtedly divides with the plastid at each cell division. 
From the dimensions and attitude of the pyrenoid when not in division, it might have been anticipated that it would be more conspicuous when viewed in life with anoptral contrast than was found with $C$. minor. This expectation was by no means fulfilled and without the precise information from the electron micrographs as to what to look for in this species, photographic demonstration of pyrenoids in living cells would have been almost impossible. With this information, after prolonged search, several favourable cells were encountered, two of which yielded the photographs for Pl. V, figs. I9 and 20.

The reason for this difficulty lies in the behaviour of the nucleus. This is commonly applied so closely to a pyrenoid as to be virtually wrapped round it, contact with other surfaces of a plastid being less conspicuous. The two sections cut in planes at right angles (P1. V, figs. 2I, 22) are self-explanatory in this respect, though it may be added that fig. 22, is part of a series of sections which at other levels show the pyrenoid as if completely surrounded by the nucleus as is also the case in Pl. VI, fig. 23. In such a condition the circular profile of a transversely cut pyrenoid may look misleadingly like a nucleolus although the delimiting surface membranes unequivocally distinguish it from a true nucleolus which these nuclei also possess. The nature of the 'nonrefringent material' which troubled the light-microscopist (cf. p. 520 above) is thus established, and with it the reason for the almost complete invisibility of pyrenoids in a majority of living cells.

As in C. minor some observations on haptonema structure have been obtained. In this species, for the first time, a ring of 8 internal fibres or tubes

\section{Explanation of Plates V, VI \\ Chrysochromulina kappa \\ Plate V}

Figs. 19, 20. Two cells photographed alive with anoptral contrast to show pyrenoids in profile (fig. 19) and end on (fig. 20). $\times 2000$.

Fig. 21. Section passing through the base of a haptonema (left) and showing a plastid $(P)$ with subtended pyrenoid $(P y)$ cut longitudinally and closely invested by the nucleus $(N)$, a branched mitochondrion $(m)$ above. Micrograph $\mathrm{B} 497, \times 20,000$.

Fig. 22. Another cell showing a transversely cut pyrenoid $(P y)$ closely invested by the nucleus $(N)$ and with a 'peculiar' Golgi body $(g)$, parts of two plastids $(P)$ and other inclusions also in the field. Micrograph B $486, \times 25,000$.

\section{Plate VI}

Fig. 23. Cell showing a transversely cut pyrenoid $(P y)$ penetrating deeply into the nucleus $(N)$ and appearing as if completely surrounded by it (contrast with figs. 21 and 22), mitochondria and part of a Golgi body visible near the base of the flagellum $(F)$. Micrograph B 1156, $\times 30,000$.

Fig. 24. Four profiles from one haptonema showing a central ring of eight fibres or tubes within the customary three concentric membranes. Micrograph B218, × 60,000. 


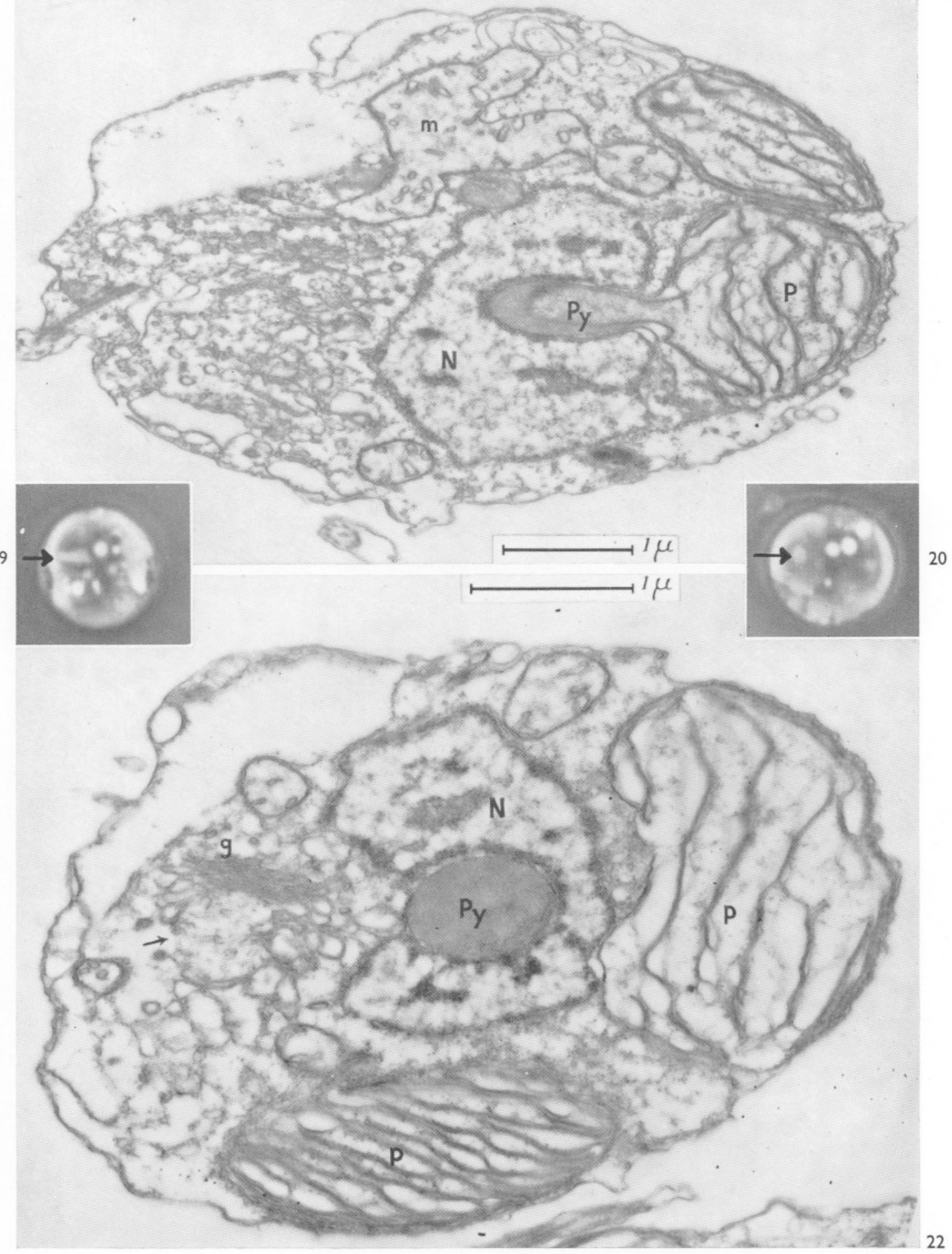

(Facing p. 524) 


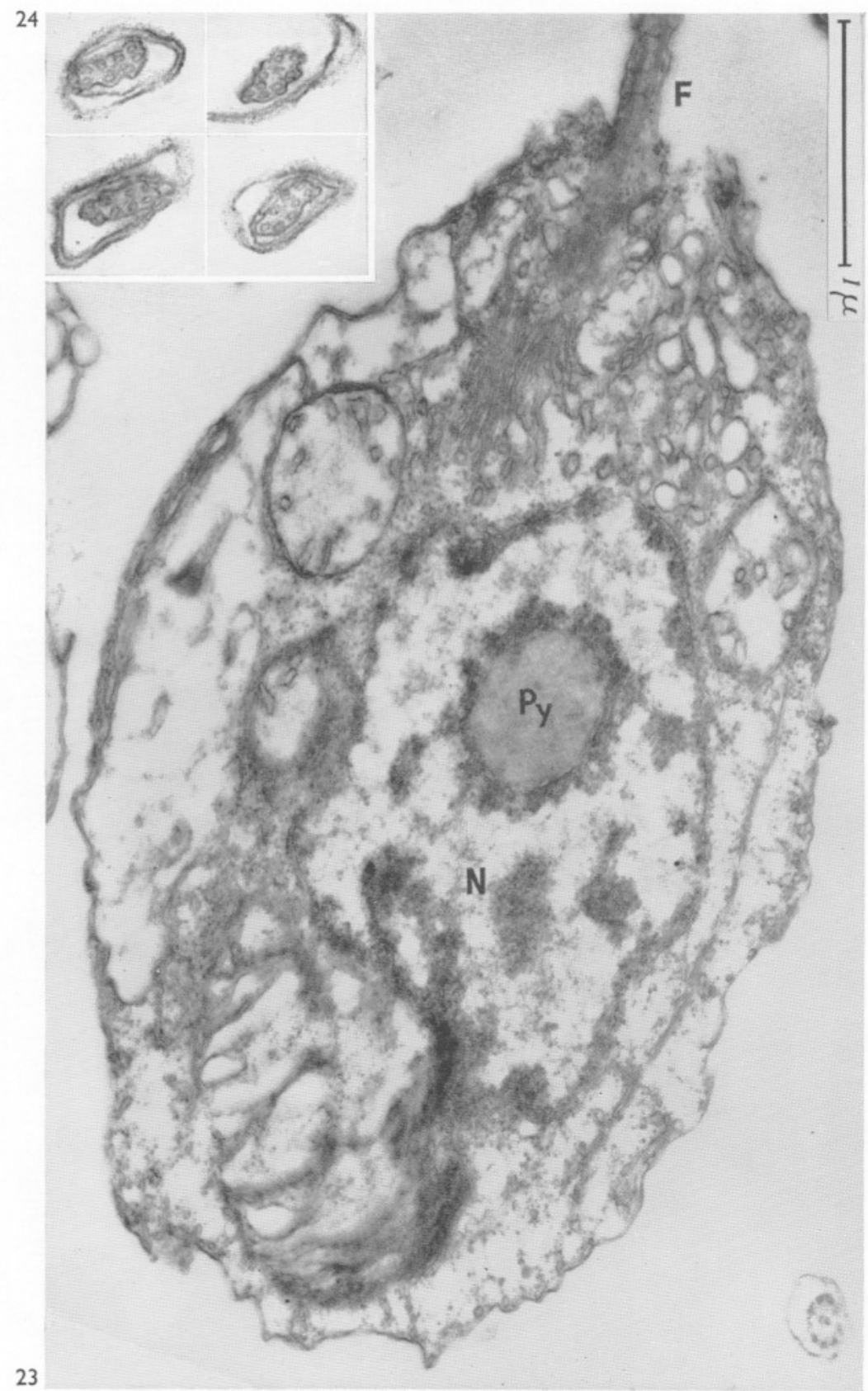


has occasionally been found (P1. VI, fig. 24). This is, however, not universal and the more usual condition of 7 internal fibres or tubes has also been seen.

Pl. V, fig. 22 and Pl. VI, fig. 23, also contain views of Golgi structure to which attention can usefully be directed. As in other cases the single Golgi body (except in dividing cells) is situated close to the bases of the appendages (fig. 23), although the precise significance of this position is still unknown. 'Peculiar' Golgi structure can also be demonstrated (P1.V, fig. 22) although this feature is much more delicate both in C. kappa and C. minor than in the other species in which this structure has been found (Parke et al. 1959; Manton \& Leedale, I96I $a$ ). The significance of this component also remains unknown and without the improvement in fixation obtained by the modified treatment it would not have been preserved.

Finally, attention should perhaps be directed to the branched mitochondrion in $\mathrm{Pl}$. V, fig. $2 \mathrm{I}$, which may indicate a growth process in some ways comparable to that recently investigated in C. brevifilum (see Manton, I96I), and to the base of the haptonema included in fig. $2 \mathrm{I}$.

\section{DISCUSSION}

It is impossible to determine by any methods at present available whether the special contact established in both these species between the nucleus and the plastid or pyrenoid surface is metabolically significant or not. If an interchange of materials between these organelles could be directly demonstrated the projecting pyrenoid itself might become interpretable in an adaptive sense as in some way facilitating this. On the other hand, the differences found among the various species examined, including these two, somewhat militates against this suggestion. A purely mechanical interpretation of the position of the nucleus seems at least as likely.

In other respects there is clearly a very considerable agreement among all the species attributed to Chrysochromulina for which the anatomy is known. These are now eight in number. Projecting pyrenoids occur in C. chiton, C. minor and C. kappa; immersed pyrenoids in C. strobilus, C. erecina, C. ephippium, C. alifera and C. brevifilum. The haptonema structure is similar in all these species except for minor numerical differences in the central strands; the commonest number is seven central strands, found in all species except $C$. strobilus which has consistently six and C. kappa which occasionally has eight. These are the two most important structures which have so far been dealt with anatomically and the only ones with which the present paper has been intimately concerned.

We are not competent to give taxonomic advice on the weight which should be put upon the morphological facts presented here. We have, however, shown why the pyrenoid is difficult to investigate effectively with the light microscope at present and its inconvenience as a major taxonomic criterion is 
obvious. The removal from apparent isolation of the condition previously known only in C. chiton is nevertheless a positive contribution towards eventual understanding of the group.

\section{SUMMARY}

Chrysochromulina minor and C. kappa have been re-investigated by means of electron microscopy of thin sections to add details of the microanatomy of pyrenoids and haptonemata, and by anoptral contrast light microscopy to study pyrenoids in living cells. In both species the pyrenoid is in the form of a diverticulum projecting from the centre of the inner face of a plastid and, in C. minor, strongly flexed to lie along it. In C. kappa the pyrenoid is commonly enveloped by the nucleus which may conceal it entirely from view in life. Some details of the behaviour of the surface membranes of plastids and pyrenoids in relation to that of the nucleus are given. The haptonema structure in both species is shown to be comparable to that of others in which this appendage is much longer, though an occasional variant with eight instead of seven central fibres or tubes has been encountered in C. kappa and is demonstrated. The presence of 'peculiar' Golgi structure is reported for both species and demonstrated for C. kappa. Some direct evidence indicating an internal origin of scales from vesicles is demonstrated in C. minor. Finally a summary is given of salient structural criteria for all the described species attributed to this genus from the marine plankton, the closest agreement as regards pyrenoid structure in the two species under investigation being with $C$. chiton.

\section{REFERENCES}

Manton, I., 1961. Some problems of mitochondrial growth. F. exp. Bot. (in the Press). MANTon, I. \& LeEdALE, G. F., I96I $a$. Further observations on the fine structure of Chrysochromulina ericina Parke \& Manton. F. mar. biol. Ass. U.K., Vol. 40, pp. $145-55$.

- 196I $b$. Observations on the fine structure of Paraphysomonas vestita with special reference to the Golgi apparatus and the origin of scales. Phycologia, Vol. I, pp. 37-57.

MANTON, I. \& PARKE, M., 1960. Further observations on small green flagellates with special reference to possible relatives of Chromulina pusilla Butcher. F. mar. biol. Ass. U.K., Vol. 39, pp. 275-98.

PARKe, M., Manton, I. \& Clarke, B., 1955. Studies on marine flagellates. II. Three new species of Chrysochromulina. F. mar. biol. Ass. U.K., Vol. 34, pp. 579-609. 1958. IV. Morphology and microanatomy of a new species of Chrysochromulina. F. mar. biol. Ass. U.K., Vol. 37, pp. 209-28. 1959. V. Morphology and microanatomy of Chrysochromulina strobilus sp.nov. F. mar. biol. Ass. U.K., Vol. 38, pp. $169-88$. 